\title{
Coherent mapping helps to identify the mechanism of an atrial tachycardia after EpicorTM high-intensity focused ultrasound ablation
}

\author{
Jan Wintrich ${ }^{1}$, Valerie Pavlicek ${ }^{1}$, Dominic Millenaar ${ }^{1}$, and Christian Ukena $^{1}$ \\ ${ }^{1}$ Saarland University Hospital and Saarland University Faculty of Medicine
}

July 16, 2020

\begin{abstract}
Pulmonary vein isolation (PVI) is of great importance to achieve rhythm control in patients with atrial fibrillation. Besides catheter-based procedures, the application of high-intensity focused ultrasound (HIFU) can be used for PVI. However, HIFU has been associated with rater low efficacy rates. We report a case of a 73-year old patient, in whom HIFU failed to maintain sinus rhythm but promoted the occurrence of a scar-related atrial tachycardia (AT). Coherent mapping with visualization of velocity vectors allowed the correct interpretation and the targeted ablation of this tachycardia. The coherent mapping function could simplify mapping of scar-related tachycardia in the future.
\end{abstract}

\section{Keywords:}

Coherent mapping - Atrial fibrillation ablation - High-intensity focused ultrasound - Scar-related tachycardia

\section{Introduction}

In patients undergoing cardiac surgery, atrial fibrillation $(\mathrm{AF})$ can complicate the postoperative course, for instance by increasing the risk of strokes and inducing hemodynamic instability (1). Subsequently, surgical techniques of AF ablation have been developed. One of these techniques is the application of highintensity focused ultrasound (HIFU) with the Epicor ${ }^{\mathrm{TM}}$ device (St Jude Medical, Maple Grove, MN, Figure 1A), which aims to create a box-lesion around the four pulmonary veins (PV). Although HIFU proved to be feasible, it is associated with a rather low rate of complete or near-complete box isolations resulting in successful pulmonary vein isolation (PVI) $(2,3)$. Moreover, cardiac surgery induces myocardial fibrosis, which promotes scar-related atrial tachycardia (AT) (4). Appropriate treatment of these complex arrhythmias is possible by three-dimensional (3D) electroanatomic mapping (EAM) that helps to understand the underlying activation pattern and to identify critical targets for ablation. However, scar tissue can significantly reduce the accuracy of this method. For instance, scarred myocardial tissue can lead to a relevant delay between the onset of the local electrogram and the time to the peak amplitude, leading to inconclusive activation maps (5). Calculation of conduction velocity vectors, which can be visualized in so-called coherent maps, might help to correctly interpret the mechanisms of these arrhythmias and allow a targeted ablation.

\section{Case report}

A 73-year-old man was referred to our hospital for ablation of a symptomatic persistent AT. Nine years ago, the patient underwent surgery for coronary artery bypass grafting and aortic valve replacement. During this surgical procedure, the patient additionally received ablation treatment performed with HIFU (Epicor, St Jude Medical, Maple Grove, MN) due to paroxysmal AF. At presentation, a dilated left ventricle with moderately reduced left-ventricular ejection fraction of $32 \%$ and a left atrial volume of $77 \mathrm{ml}$ with only 
mild mitral regurgitation was detected. The biological aortic valve prosthesis was in proper location and well-functioning with a mean aortic valve pressure gradient of $21 \mathrm{mmHg}$.

During the electrophysiological procedure, a 7 French (F) 10-pole deflectable catheter was placed into the coronary sinus (CS) via femoral venous approach, which confirmed the left-atrial AT with a cycle length (CL) of $280 \mathrm{~ms}$ and a 2:1 atrioventricular conduction. After fluoroscopy-guided double trans-septal punctures, a high-density mapping catheter (PENTARAY ${ }^{\odot}$, Biosense Webster, CA, USA) and a Smarttouch SF irrigatedtip ablation catheter (Smarttouch SF ${ }^{\circledR}$, Biosense Webster, CA, USA) were placed in the left atrium (LA), respectively. EAM was performed with the CARTO 3 CONFIDENSE system (Biosense Webster, CA, USA). Low voltage zones (LVZ) were defined as areas with a bipolar peak-to-peak voltage amplitude of $<0.5$ $\mathrm{mV}$. Notably, LVZ were identified along the Epicor ${ }^{\mathrm{TM}}$ ablation line. However, there were multiple gaps in the ablation line, particularly located among the anterior segments of the right PV and the posterior wall (Figure 1). Activation mapping depicted $83 \%$ of the AT-CL with the earliest activation ostial of the LA appendage suggestive of a macro-reentry mechanism. The integration of vector and velocity information (COHERENT ${ }^{\mathrm{TM}}$ technology) confirmed a focal activation with a conduction block of the LA roof, as shown in Figure 2 and Supplement video 1. Ablation (30 Watts) was started at the earliest site of activation, resulting in prompt termination of the AT into sinus rhythm. Furthermore, the Epicor ${ }^{\mathrm{TM}}$ ablation line was completed by ablating the posterior wall and the anterior segments of the right PV. As a result, isolation of all PVs and the posterior wall was achieved (Figure 3).

\section{Discussion}

Catheter-based PVI has emerged as a cornerstone in AF therapy and improves clinical outcomes compared to medical treatment in selected patients (6). However, roughly $50 \%$ of all patients experience recurrence of $\mathrm{AF}$ within 2 years (7). Thus, new techniques of AF ablation have been investigated in the past, such as the minimal-invasive epicardial HIFU electroablation treatment. First studies reported rather high efficacy rates, with $83-85 \%$ freedom from atrial arrhythmias 6 months after treatment $(8,9)$. In contrast, the recurrence rate of atrial arrhythmias was found to be much higher in more recent studies $(2,3,10)$. Furthermore, rate of complete or near-complete box isolation resulting in successful PVI 6 months after HIFU AF ablation was less than $40 \%$ (2). Accordingly, in this case, multiple gaps have been found along the Epicor ${ }^{\mathrm{TM}}$ ablation line, which resulted in the occurrence of a focal AT and persistent electrical connection of the PV. Activation mapping of these complex scar-related AT can be challenging because of difficulties in the accurate annotation of multicomponent electrograms, the correct differentiation between active and passive diastolic activity, and the dependency on a window of interest with arbitrarily defined early and late activation (11). Consequently, a new activation mapping algorithm has been developed that identifies and highlights zones of slow or no conduction, and calculates the most coherent pattern of activation (4). In the present case, the application of this new technical feature helped to interpret the mechanism of the AT and to identify the critical site for ablation.

\section{References}

1. Dobrev D, Aguilar M, Heijman J, Guichard J-B, Nattel S. Postoperative atrial fibrillation: mechanisms, manifestations and management. Nat Rev Cardiol. 2019;16(7):417-36.

2. Garcia R, Sacher F, Oses P, Derval N, Barandon L, Denis A, Hocini M, Roques X, Haïssaguerre M, Labrousse L, Jaïs P. Electrophysiological study 6 months after EpicorTM high-intensity focused ultrasound atrial fibrillation ablation. J Interv Card Electrophysiol. 2014;41(3):245-51.

3. Pozzoli A, Benussi S, Anzil F, Taramasso M, Privitera YA, Cianflone D, Della Bella P, Alfieri O. Electrophysiological efficacy of Epicor high-intensity focused ultrasound. Eur J Cardiothorac Surg. 2012;42(1):12934; discussion 134.

4. Vicera JJB, Lin Y-J, Lee P-T, Chang S-L, Lo L-W, Hu Y-F, Chung F-P, Lin C-Y, Chang T-Y, Tuan T-C, Chao T-F, Liao J-N, Wu C-I, Liu C-M, Lin C-H, Chuang C-M, Chen C-C, Chin CG, Liu S-H, et al. Identification of critical isthmus using coherent mapping in patients with scar-related atrial tachycardia. J 
Cardiovasc Electrophysiol. 2020;31(6):1436-47.

5. Del Carpio Munoz F, Buescher T, Asirvatham SJ. Teaching points with 3-dimensional mapping of cardiac arrhythmias: taking points: activation mapping. Circ Arrhythm Electrophysiol. 2011;4(3):e22-5.

6. Marrouche NF, Brachmann J, Andresen D, Siebels J, Boersma L, Jordaens L, Merkely B, Pokushalov E, Sanders P, Proff J, Schunkert H, Christ H, Vogt J, Bansch D. Catheter ablation for atrial fibrillation with heart failure. N Engl J Med. 2018;378(5):417-27.

7. Packer DL, Mark DB, Robb RA, Monahan KH, Bahnson TD, Poole JE, Noseworthy PA, Rosenberg YD, Jeffries N, Mitchell LB, Flaker GC, Pokushalov E, Romanov A, Bunch TJ, Noelker G, Ardashev A, Revishvili A, Wilber DJ, Cappato R, et al. Effect of catheter ablation vs antiarrhythmic drug therapy on mortality, stroke, bleeding, and cardiac arrest among patients with atrial fibrillation: the CABANA randomized clinical trial. JAMA. 2019;321(13):1261-74.

8. Groh MA, Binns OA, Burton HG 3rd, Ely SW, Johnson AM. Ultrasonic cardiac ablation for atrial fibrillation during concomitant cardiac surgery: long-term clinical outcomes. Ann Thorac Surg. 2007;84(6):1978-83.

9. Ninet J, Roques X, Seitelberger R, Deville C, Pomar JL, Robin J, Jegaden O, Wellens F, Wolner E, Vedrinne C, Gottardi R, Orrit J, Billes M-A, Hoffmann DA, Cox JL, Champsaur GL. Surgical ablation of atrial fibrillation with off-pump, epicardial, high-intensity focused ultrasound: results of a multicenter trial. J Thorac Cardiovasc Surg. 2005;130(3):803-9.

10. Klinkenberg TJ, Ahmed S, Ten Hagen A, Wiesfeld ACP, Tan ES, Zijlstra F, Van Gelder IC. Feasibility and outcome of epicardial pulmonary vein isolation for lone atrial fibrillation using minimal invasive surgery and high intensity focused ultrasound. Europace. 2009;11(12):1624-31.

11. Anter E, Duytschaever M, Shen C, Strisciuglio T, Leshem E, Contreras-Valdes FM, Waks JW, Zimetbaum PJ, Kumar K, Spector PS, Lee A, Gerstenfeld EP, Nakar E, Bar-Tal M, Buxton AE. Activation Mapping With Integration of Vector and Velocity Information Improves the Ability to Identify the Mechanism and Location of Complex Scar-Related Atrial Tachycardias. Circ Arrhythm Electrophysiol. 2018;11(8):e006536.

\section{Figure Legends}

Figure 1. Atrial fibrillation ablation with Epicor ${ }^{\mathrm{TM}}$ high-intensity focused ultrasound aims to create a box isolation around the four pulmonary veins. Herefore, an ultraclinch device is placed around the pulmonary veins, and closed in front of the right superior pulmonary vein (A). Accordingly, the voltage map of the left atrium reveals a line of low-voltage zones around the pulmonary veins that represent the Epicor ${ }^{\mathrm{TM}}$ ablation line $(\mathrm{A}+\mathrm{B})$. However, there are multiple gaps along the line, particularly among the anterior segments of the right pulmonary vein (A, RAO projection), and among the posterior wall (B, PA projection). Abbreviations: LIPV = left inferior pulmonary vein; LSPV $=$ left superior pulmonary vein; $\mathrm{PA}=$ posterior anterior; $\mathrm{RAO}$ $=$ right anterior oblique; RIPV $=$ right inferior pulmonary vein; RSPV $=$ right superior pulmonary vein .

Figure 2. Activation (A) and coherent mapping (B) of the left atrium demonstrate a focal activation pattern of the atrial tachycardia. The tachycardia originates from a gap in the Epicor ${ }^{\mathrm{TM}}$ ablation line $\left(^{*}\right)$, which is located right at the transition to the left atrial appendage (colored in blue). In the coherent map, zones of slow or no conduction are colored in brown. The corresponding intracardial signals at the earliest activation site are shown in the bipolar derivative MAP 1-2 and the unipolar derivative MAP 1, respectively. Abbreviations: LAA = left atrial appendage; LIPV = left inferior pulmonary vein; LSPV = left superior pulmonary vein; RIPV $=$ right inferior pulmonary vein; RSPV $=$ right superior pulmonary vein.

Figure 3 . The Epicor ${ }^{\mathrm{TM}}$ line was completed by ablation points at the posterior wall and the anterior segments of the right PV. After ablation, the voltage map of the left atrium confirms the successful isolation of all pulmonary veins and the posterior wall (A, RAO projection; $\mathrm{B}$, PA projection). Abbreviations: LIPV = left inferior pulmonary vein; LSPV = left superior pulmonary vein; $\mathrm{PA}=$ posterior anterior; $\mathrm{RAO}=$ right anterior oblique; RIPV = right inferior pulmonary vein; RSPV = right superior pulmonary vein. 


\section{Figure 1.}

\section{Hosted file}

image1.emf available at https://authorea.com/users/342431/articles/469227-coherent-mappinghelps-to-identify-the-mechanism-of-an-atrial-tachycardia-after-epicortm-high-intensityfocused-ultrasound-ablation

\section{Figure 2.}

\section{Hosted file}

image2.emf available at https://authorea.com/users/342431/articles/469227-coherent-mappinghelps-to-identify-the-mechanism-of-an-atrial-tachycardia-after-epicortm-high-intensityfocused-ultrasound-ablation

\section{Figure 3.}

\section{Hosted file}

image3.emf available at https://authorea.com/users/342431/articles/469227-coherent-mappinghelps-to-identify-the-mechanism-of-an-atrial-tachycardia-after-epicortm-high-intensityfocused-ultrasound-ablation

\section{Appendices}

Supplement video 1. 